\title{
REVISÃO TEXTUAL E GÊNERO ACADÊMICO TESE DE DOUTORADO: A NEGOCIAÇÃO DE SENTIDOS COMO CERNE DA INTERAÇÃO
}

\author{
Patrícia Souza Lemos* \\ Márcia Helena de Melo Pereira*
}

RESUMO: Na esfera acadêmica é intensa a produção de trabalhos, principalmente escritos, os quais devem estar adequados do ponto de vista da norma culta. Assim, para promover adequações linguístico-discursivas no texto, costuma ser necessária sua revisão textual. Diante disso, nosso principal objetivo é refletir sobre a relevância da negociação entre interlocutores para a construção de sentido, no processo de produção do gênero acadêmico tese de doutorado. Assim, selecionamos duas teses de doutorado, dando destaque a alguns excertos de cada uma, nos quais contêm interações sobre o sentido, comparando os mesmos trechos revisados com a versão pós-ajustes. Teoricamente, adotamos uma perspectiva textual, com base em autores como Costa Val (1999), Marcuschi (2008), Antunes (2010), entre outros, pois cremos que o revisor funda-se em recursos linguísticos na realização de seu trabalho, e uma perspectiva sociointeracionista bakhtiniana, uma vez que esse gênero possui caráter essencialmente dialógico, interacional e polifônico. Com base em nossas análises, salientamos, pois, a relevância da negociação entre autor e revisor, na etapa da revisão textual, para a configuração do gênero discursivo tese de doutorado, principalmente porque o diálogo representa um caráter constitutivo da própria linguagem e essencial para a efetivação do sentido.

PALAVRAS-CHAVE: Revisão textual; Negociação; Gênero discursivo tese de doutorado.

\section{Introdução}

Nos espaços de ensino superior, seja em nível de graduação ou pós-graduação, existe uma intensa produção de trabalhos acadêmicos, como artigo técnico-científico, monografia, TCC, dissertação de mestrado, tese de doutorado, dentre outros, os quais representam mais do que difusão de conhecimentos, mas, principalmente, marcam situações de comunicação, sendo, portanto, textos que se materializam em situações sociocomunicativas (MARCUSCHI, 2008). Em uma perspectiva bakhtiniana, salientamos que, na comunicação verbal, em todas as esferas de nossas atividades, sempre recorremos a um gênero discursivo, seja da oralidade ou da escrita, sendo os gêneros discursivos os tipos relativamente estáveis de

\footnotetext{
* Doutoranda em Linguística pela Universidade Estadual do Sudoeste da Bahia (Uesb). Mestre em Linguística pela mesma Instituição.

** Doutora em Linguística Aplicada pela Universidade Estadual de Campinas (Unicamp). Professora Titular da Universidade Estadual do Sudoeste da Bahia (Uesb).
} 
enunciados ${ }^{1}$ produzidos por um indivíduo, desde uma conversa informal (diálogo) até a escrita de um texto como uma tese de doutorado, por exemplo (BAKHTIN, 2011).

Os gêneros que circulam na esfera acadêmica necessitam apresentar uma linguagem adequada ao seu ambiente de produção/circulação, sendo necessária, por vezes, a revisão do texto. Dessa forma, verificamos, então, uma preocupação relacionada à linguagem, uma vez que se trata de gêneros originados em situações de "um convívio cultural mais complexo e relativamente muito mais desenvolvido e organizado" (BAKHTIN, 2011, p. 263) e, além disso, encontram-se submetidos a muitas sanções em relação a uma escrita apropriada do ponto de vista da norma culta.

Como afirma Possenti (1996), é o papel da escola ensinar a norma considerada padrão, instrumentalizar os alunos, a fim de que saibam se expressar adequadamente, nas diferentes situações de comunicação, sejam elas mais formais ou menos formais. Ademais, considerando que a língua de prestígio ensinada no ambiente escolar é também a variedade utilizada pelas classes dominantes, para os indivíduos, conhecê-la e utilizá-la implica o acesso a espaços de poder. Dessa maneira, não é diferente nos espaços de ensino superior, pois é esperado de estudantes de graduação e pós-graduação que saibam escrever utilizando a norma culta acadêmica. Entretanto, ressaltamos que, independentemente de possuir domínio da norma ou não, qualquer escrevente pode cometer equívocos, deslizes, erros de digitação, ambiguidades, falta de clareza etc., ao produzir textos, sendo aconselhável realizar uma revisão textual, a fim de adequar a produção escrita (LEMOS; PEREIRA, 2017, p. 220-221).

A revisão textual apresenta-se, então, como parte do processo de produção do texto, uma de suas etapas (OLIVEIRA, 2016), além de seu planejamento, da produção escrita inicial, da reescrita etc., até que se chegue a uma versão considerada 'final' - para publicação ou apresentação a um público, como a banca avaliadora, no caso de trabalhos acadêmicos. Com base na Linguística Textual, o texto não deve ser encarado como um produto acabado, mas como um processo (BENTES, 2001), no qual o sentido não se encontra pronto, porém é construído pelos parceiros na comunicação - especialmente pelo leitor. Nessa perspectiva, o revisor surge como um leitor profissional (SALGADO, 2017), sendo, ainda, um profissional especializado que lida com textos de outrem, possuindo formação acadêmica na área de linguagem e experiência em revisão, pois, em geral, são indivíduos que trabalham ou já trabalharam em espaços editoriais (OLIVEIRA, 2016; YAMAZAKI, 2009).

\footnotetext{
${ }^{1}$ Enunciado é tomado, aqui, como o dito, o ato de enunciar; representando, dessa maneira, a transformação da língua em discurso (BAKHTIN, 2011).
} 
Destacamos que, embora os objetivos do revisor se distingam dos de outros leitores, visto que analisa o texto à procura de "deslizes" de ordem linguística, no intuito de solucionálos e de propor sugestões, assim como qualquer outro leitor o revisor busca compreender o texto, construir sentido(s), pois revisar é mais do que corrigir supostos erros, mas, acima de tudo, é ler a fim de compreender, é ter dúvidas que possam ser discutidas com o autor, é analisar para que possa apontar caminhos alternativos, enfim, implica "trabalhar com os aspectos formais do texto, identificar problemas que são de ordem discursiva, pois vários equívocos de ordem interacional interferem na funcionalidade do texto" (RODRIGUES, 2010, p. 159); portanto, revisar significa participar juntamente com o autor da construção do(s) sentido(s) daquele texto, já que comunicação é interação entre os interlocutores.

No âmbito da revisão de textos acadêmicos, o revisor, muitas vezes, trabalha com textos de diferentes áreas do conhecimento em relação a sua área de formação, sendo necessário ser também um pesquisador. Além disso, ao realizar intervenções nos textos que revisa, deve estar em contato com o autor, no intuito de discutir sobre a pertinência ou não de suas ações. Ademais, muitas vezes, em razão dos curtos prazos para entrega dos textos e de dificuldade para encontros presenciais, em virtude das distâncias geográficas por exemplo, o diálogo entre autor e revisor a respeito do texto acaba sendo realizado de forma virtual, isto é, recorrem à inserção de balões no próprio texto, possibilitados pelas ferramentas do editor de textos Word, para negociarem, interativamente, pontos que merecem alguma discussão, principalmente no que tange ao sentido.

Assim, de acordo com Marcuschi (2008, p. 242), “[...] o sentido não está no leitor, nem no texto, nem no autor, mas se dá como um efeito das relações entre eles e das atividades desenvolvidas". Dessa forma, ao considerar os efeitos de sentido fruto dessa relação, em parceria, acreditamos que, no caso da revisão, a negociação, por meio do diálogo - interação - entre autor e revisor, seja extremamente relevante para que o profissional não mude as palavras do autor, uma vez que, conforme Ribeiro (2016, p. 74), as intervenções realizadas pelo revisor podem alterar "profundamente os dizeres do autor".

Dessa maneira, perguntamo-nos sobre o seguinte: qual o papel da negociação na interação entre autor e revisor, tendo em vista a configuração do gênero discursivo em processo de revisão? Diante desse questionamento, nosso principal objetivo é refletir, aqui, sobre a relevância da negociação entre interlocutores para a construção de sentido, no processo de produção do gênero acadêmico tese de doutorado, em etapa de revisão, numa perspectiva sociointeracionista bakhtiniana, uma vez que esse gênero possui caráter essencialmente dialógico, interacional e polifônico. 
No tocante à metodologia, ressaltamos, com base em Prodanov e Freitas (2015, p. 48), que a "[...] pesquisa científica é uma atividade humana [...]", com vistas ao conhecimento e compreensão de um fenômeno, visando, ainda, fornecer respostas àquilo que se investiga. Nesse sentido, do ponto de vista dos procedimentos, trata-se de uma pesquisa bibliográfica, ou seja, produzida com base em materiais já publicados a respeito da temática, a fim de produzir uma reflexão sobre o assunto pesquisado; no tocante ao objetivo, caracteriza-se como um estudo descritivo, ao reunirmos dados buscando organizá-los, descrevê-los, interpretálos, enfim analisá-los (PRODANOV; FREITAS, 2015, p. 54, 52). Para a produção deste artigo, selecionamos duas teses de doutorado ${ }^{2}$ em etapa de revisão: uma concentrada na área de conhecimento das ciências médicas e outra das ciências humanas, tendo sido revisadas por dois profissionais revisores diferentes. Para nossas análises, escolhemos trechos dessas duas teses, com balões interativos, dos quais fizemos prints de tela, que apresentam diálogos entre autor e revisor, comparando, ainda, com a versão pós-revisão.

Além desta introdução, na qual contextualizamos o estudo, o artigo apresenta outras quatro seções. Assim, na primeira seção, caracterizamos, ainda que brevemente, a atividade de revisão textual. $\mathrm{Na}$ segunda seção, delineamos o gênero discursivo tese de doutorado, baseando-nos especialmente em Bakhtin. Na terceira seção, expomos nossa principal fundamentação teórica, permeada por questões não apenas de ordem discursiva, mas também linguística, como a noção de textualização. Na quarta seção, analisamos nossos dados, recortes de trechos de teses de doutorado em etapa de revisão, à luz das bases teóricas. Por fim, apresentamos nossas considerações finais, ressaltando ser a negociação um dos principais aspectos da revisão textual, visando à configuração do gênero discursivo.

Neste sentido, discutimos, na próxima seção, sobre a atividade de revisão textual, apresentando, brevemente, seus principais aspectos.

\section{A revisão textual - muito mais que correção gramatical}

A atividade de revisão textual caracteriza-se principalmente pelo trabalho com textos escritos, sejam eles acadêmicos, científicos, literários, jornalísticos, dentre outros. Essa atividade representa mais do que ler um texto à procura de "erros" gramaticais. Embora não seja possível precisar quando surgiu a revisão de textos, especialmente na condição de atividade profissional, conforme destaca Guedes (2013), podemos relacioná-la com os primeiros

\footnotetext{
2 Projeto submetido à apreciação e aprovação do Comitê de Ética em Pesquisa (CEP), da Uesb com cadastro no Certificado de Apresentação para Apreciação Ética (CAAE).
} 
registros de escrita, uma vez que o trabalho do revisor é realizado em textos primordialmente escritos.

Destacamos que a invenção da escrita representa uma nova atitude social, carregada de prestígio e poder (CÂMARA JR., 1975). Logo, o estabelecimento da gramática implica a existência de marcas linguísticas das classes consideradas superiores, as quais possuem maior destaque (CÂMARA JR., 1975). Assim, em nossos dias, no mundo acadêmico, em relação à produção de textos, consideramos que graduandos e pós-graduandos ocupam lugar de destaque social, dessa forma sua escrita deve “obedecer” à norma de prestígio.

Segundo Oliveira (2016), em contribuição para o desenvolvimento das civilizações e da ciência moderna, a escrita propiciou o surgimento de duas perspectivas: instrumental e de mudança conceitual. A primeira, a partir da prensa gutemberguiana, inventada no século XV, que permitiu compor um vasto acervo de obras, livres dos erros dos copistas e reproduzidas em quantidade ilimitada; a segunda, por meio de "[...] uma nova compreensão da distinção conceitual entre o dado, encontrado nos textos ou na natureza, e as percepções e interpretações subjetivas do leitor" (OLIVEIRA, 2016, p. 32). Além disso, o jornalismo - gazetas, folhetos de notícias, os libelos etc. - também foi possibilitado pela existência da escrita (MELO, 2005).

É, portanto, em um contexto de democratização da cultura, de sucesso da imprensa, de processo de industrialização, de regularidade das publicações que surge a figura do revisor (MELO, 2005). Atualmente, a atividade de revisão e o profissional revisor têm sido associados a espaços como jornais e editoras, isto porque é nesses espaços que a atividade encontrase formalizada e institucionalizada (OLIVEIRA, 2016; RIBEIRO, 2009; YAMAZAKI, 2009; GUEDES, 2013). No entanto, quando se trata da revisão de gêneros acadêmicos, geralmente é feita por profissionais que trabalham como freelancer, sendo prestadores de serviço, sem vínculo empregatício, mas que em algum momento tiveram contato com essa atividade por meio do trabalho em editoras ou jornais, possuindo formação acadêmica, além de experiência.

Ao abordar a produção de um gênero acadêmico como uma tese de doutorado, podemos afirmar que antes de levá-lo a público, sem correr o risco de apresentar inadequações, aconselha-se que ele passe, no mínimo, por uma "correção" (SERRANO, 2011), caso contrário alguns desvios poderão ser detectados, desvios provocados em função de desatenção, descuido, cansaço, dificuldades em manejar a língua vernácula em sua modalidade escrita (gramaticalmente), dentre outras razões que podem comprometer a escrita, visto que aqueles 
que apresentam desvios gramaticais graves geralmente são vistos com desconfiança quanto à sua qualidade.

Destacamos, ainda, que é possível identificar as intervenções do revisor nos textos, com base em Ribeiro (2009), sendo dos tipos resolutivo, indicativo, classificatório e interativo. Dessa forma, a revisão do tipo resolutiva ocorre quando o profissional 'resolve o problema' de forma definitiva, como no caso de uma concordância, uma acentuação de palavra etc. - casos em que não necessita do aval do autor. A revisão do tipo indicativa caracterizase pela indicação, sinalização daquilo que deve ser ajustado no texto pelo autor.

Quanto à intervenção do tipo classificatório, “o revisor utiliza metalinguagem para indicar os problemas" (RIBEIRO, 2009, p. 6), isto é, classifica o tipo de ocorrência para que se tome conhecimento do tipo de desvio cometido, a fim de saber como intervir na ocorrência. Por fim, a intervenção do tipo interativo, e que mais nos interessa aqui, mediante a inserção de balões no texto, por meio dos quais o revisor pode dialogar com o autor e viceversa, uma vez que "[...] subsidia muito mais a construção da autoria e a aprendizagem da escrita" (RIBEIRO, 2009, p. 6).

Portanto, visando promover adequação e qualidade ao texto, do ponto de vista ortográfico-gramatical e, também, discursivo, ganha destaque a revisão textual, no processo de produção da pesquisa. Na seção seguinte, delineamos o gênero acadêmico tese de doutorado, dando destaque principalmente aos pilares que o sustentam, como propõe Mikhail Bakhtin.

\section{0 gênero acadêmico tese de doutorado}

$\mathrm{Na}$ constituição do gênero discursivo Tese de Doutorado, bem como na de qualquer outro gênero, é importante que sejam levados em consideração alguns aspectos: os interlocutores, a situação sociocomunicativa, o espaço em que circula, sua(s) finalidade(s) etc., além dos três pilares sobre os quais se assenta: conteúdo temático, estilo da linguagem e estrutura composicional (BAKHTIN, 2011). Trata-se de um gênero discursivo primordialmente escrito e que tem origem do domínio discursivo acadêmico (MARCUSCHI, 2008), portanto, para nós, um gênero acadêmico.

Destacamos, ainda, que, embora os gêneros discursivos não devam ser considerados modelos estanques, visto que são "formas culturais e cognitivas de ação social corporificadas de modo particular na linguagem” (MARCUSCHI, 2008, p. 156), não podemos desconsiderar, também, que eles possuem identidade, o que, muitas vezes, condiciona nossas escolhas linguísticas (léxico, grau de formalidade, natureza dos temas), como lembra Bronckart (2001) reafirmado por Marcuschi (2008). Em outras palavras, sobre a escrita de uma tese de 
doutorado, originada no espaço acadêmico, onde tem primazia a norma linguística chamada culta, as escolhas linguísticas acabam sendo condicionadas pela variedade que prevalece nesse espaço, obedecendo a uma linguagem culta, científica, clara, objetiva etc.

Desse modo, o doutorando necessita conhecer a norma culta de sua língua vernácula, além, principalmente, de estar apto à carreira de pesquisador, em um processo, muitas vezes, bastante solitário, no qual poderá contar com algum auxílio (SERRANO, 2011). A respeito desse auxílio, podemos citar a figura do orientador, da banca qualificadora/examinadora e, por vezes, do revisor de textos ou algum leitor que possua conhecimentos teóricos. Assim, ressaltamos que o processo de produção da tese de doutorado, na condição de texto escrito, ocorre desde o início da pesquisa, com a construção do projeto de pesquisa, com o cumprimento dos créditos, com os seus primeiros apontamentos, notas de suas pesquisas e discussões teóricas, até se chegar à tese propriamente dita, organizada conforme os padrões exigidos pela academia e convencionados socialmente.

Consoante Bakhtin (2011, p. 261), a utilização da linguagem se efetiva mediante os enunciados, orais ou escrito, concretos e irrepetíveis, em dada esfera da atividade humana; a enunciação, por sua vez, representa a cena em que ocorre o enunciado - um dito/escrito transformado em discurso no ato de seu proferimento, o qual ocorre em uma situação sociodiscursiva. Assim, “o enunciado não é uma unidade convencional, mas uma unidade real, precisamente delimitada da alternância dos sujeitos do discurso", sendo o diálogo, em virtude de sua simplicidade e precisão, "a forma clássica de comunicação discursiva” (BAKHTIN, 2011, p. 275).

Ainda de acordo com Bakhtin (2011), os gêneros do discurso possuem três principais bases para seu estabelecimento, quais sejam: estrutura composicional, estilo de linguagem e conteúdo temático. Importante mencionarmos, também, que o autor russo diferencia gêneros primários e secundários, ou seja, aqueles mais simples (não simplórios), utilizados no cotidiano, e os mais complexos, originados de situações mais organizadas e desenvolvidas, respectivamente, constituindo artefatos produzidos sociocognitivamente, tendo em vista o atendimento de objetivos comunicativos em diversas situações.

Nesse sentido, quanto às bases que sustentam o gênero (estrutura composicional, estilo de linguagem e conteúdo temático), neste caso a tese de doutorado, destacamos que a organização do texto corresponde ao pilar 'estrutura composicional' do gênero; trata-se da configuração própria desse tipo de enunciado, assim estabilizado sócio-historicamente (BAKHTIN, 2011), pois o texto deve ser apresentado de forma ordenada, homogênea, articulado em uma só peça, sendo resultado de um estudo original, visando alcançar o título de doutor(a) 
em área específica (SERRANO, 2011), devendo ser organizado conforme especificidades do campo de comunicação a que pertence, possuindo, assim, uma organização própria e apropriada, contendo introdução, desenvolvimento e conclusão, apresentando, ainda, em seu interior, uma problematização, justificativa, objetivos, metodologia, resultados/discussão, conclusão, referências etc.

Sobre o estilo da linguagem no texto, é interessante ressaltar que os gêneros acadêmicos, como artigo científico, TCC, dissertação, tese etc., primordialmente escritos, são mais complexos, menos flexíveis do ponto de vista da aparição da individualidade do autor, que, por sua vez, deverá utilizar uma linguagem na modalidade escrita considerada acadêmica, científica e formal. No entanto, apesar de a tese ser um gênero relativamente 'fechado', isso não significa dizer que o estilo individual não possa aparecer, pois "a própria escolha de determinada forma gramatical pelo falante [escrevente] é um ato estilístico" (BAKHTIN, 2011, p. 269); e, considerando o fato de estarmos tratando de teses em etapa de revisão, vale dizer que, quase sempre, o revisor está atento à aparição do autor no texto, ainda que seja para suprimi-la.

Já o conteúdo temático se refere à orientação discursiva, ao aspecto direcionador da comunicação e não apenas o seu tema (BAKHTIN, 2011; RIBEIRO, 2010). Dessa maneira, na tese a discussão sobre determinado objeto de pesquisa representa o ponto de partida, pois é com base nessa definição que se desenvolve a redação do texto, ou seja, definem-se o local de desenvolvimento da pesquisa, a metodologia a ser seguida, objetivos a serem alcançados, análises e conclusão (SERRANO, 2011). De acordo com Motta-Roth e Hendges (2010), na produção de textos acadêmicos é a leitura que alimenta a escrita; assim, é necessário, na produção da tese, que o pesquisador realize leituras relevantes, relacionadas ao tema desenvolvido, além disso aconselha-se que sempre procure consultar as fontes primárias.

Neste aspecto das leituras realizadas pelo pesquisador, os gêneros acadêmicos caracterizam-se por serem textos que dialogam com outros textos (BAKHTIN, 2011, 2014), primeiro porque o objeto a ser estudado não é desconhecido por todos (mesmo que haja originalidade na pesquisa); segundo, há necessidade de realizar uma contextualização teórica e histórica no campo pesquisado; por último, utilizar uma boa base bibliográfica significa reconhecer a autoridade científica e, portanto, atribuir autoridade ao próprio texto (SERRANO, 2011).

Dessa maneira, vale destacar esse caráter essencialmente dialógico, interacional e polifônico (BAKHTIN, 2011, 2014, 2018) do gênero acadêmico tese de doutorado, principalmente em virtude de sua produção ser resultante da interação, da relação entre 
indivíduos/discursos/enunciados, sob o olhar atento do orientador, sob o olhar perscrutador da banca, sob o olhar especializado do revisor, além de serem tomadas como base para discussão várias referências, ou seja, produções científicas de autores que corroboram a pesquisa ou mesmo que sejam de opiniões adversas, a fim de contrapô-las.

Ao produzir uma tese de doutorado, almeja-se a obtenção do título de doutor, além de maior qualificação no mercado de trabalho e o fornecimento de contribuições à área de pesquisa (SERRANO, 2011), sendo esses os principais objetivos do pós-graduando. Ao longo desse processo, a tese, assim como qualquer outro gênero acadêmico com vistas ao alcance de um grau de estudos, passa por etapas, ou seja, escrita, reescrita, textualização, correção, revisão, apreciação das bancas de qualificação e defesa etc. até que se chegue a uma versão considerada 'final', para depósito junto ao curso/programa. É, pois, nas etapas finais que identificamos a participação/parceria do revisor de gêneros acadêmicos que atua na condição de freelancer, intervindo em questões técnicas, linguísticas e discursivas, visando à configuração do gênero.

Na seção seguinte, expomos nossa fundamentação teórica, tratando sobre a produção de sentido(s) baseada em recursos linguísticos e na sociointeração.

\section{Construção de sentido(s) na revisão textual: fenômeno linguístico e sociointeraci- onal}

A construção de sentido(s), na etapa da revisão de textos, deve ser considerada sob uma perspectiva textual e sociointeracional. Textual porque o revisor, para processar sua compreensão do texto, vale-se, dentre outros, de recursos linguísticos, como a posição de uma vírgula, a seleção de vocábulos, o uso de conjunções, a fim de observar e identificar construções ambíguas, obscuras, com pouca clareza etc., e, assim, propor ajustes, reformulações, substituições, supressões etc. Sociointeracional porque, nesse processo de compreensão do revisor, muitas vezes, necessita 'dialogar' com o autor do texto, negociar sentidos, uma vez que algumas informações podem não ficar completamente claras para este profissional, na condição de leitor com objetivos específicos.

Emerge, dessa forma, uma questão para nós: se um revisor, sendo da área de Letras, é contratado para revisar um trabalho de outra área, como da área médica ou de exatas, por exemplo, não possuindo conhecimentos específicos, como será capaz de lidar com o(s) sentido(s) do texto? Ao considerarmos o sentido o resultado de uma negociação, na etapa da revisão textual, e seguirmos uma perspectiva linguístico-discursiva-interacional de construção/negociação desse sentido, adotamos também a noção de textualização, isto é, o processo 
de produção e interpretação dos textos (COSTA VAL, 2004), como parte de nossas reflexões sobre as compreensões e negociações decorrentes da interação autor-revisor, especialmente no processo de produção do gênero tese de doutorado.

Em consonância com Marcuschi (2008), dizemos que o texto, para funcionar como tal, sustenta-se em seu contexto situacional e nas relações semânticas que se estabelecem em seu interior, lembrando que o contexto situacional, como destaca o próprio autor, não equivale ao entorno físico simplesmente, mas às questões referentes à cognição, às relações sociais, culturais, históricas etc. Nesse sentido, o texto possui relações situacionais e cotextuais, sendo o contexto concebido como " [...] uma rede de textos que dialogam tanto de modo negociado como conflituoso. Contrato e conflito fazem parte dos movimentos da produção de sentido" (MARCUSCHI, 2008, p. 87), ou seja, a construção de sentidos pode ser ajustada, havendo concordância ou discordância entre interlocutores - o que faz parte da comunicação.

No que tange à perspectiva textual, na construção de sentido(s) pelo revisor de textos, baseamo-nos na textualidade como um dos fundamentos desse processo. Ou seja, ao tomar o texto como unidade comunicativa, assumimos a textualidade como um conjunto de características ou fatores que fazem com que um texto seja considerado um texto e não uma sequência aleatória de frases (COSTA VAL, 1999; MARCUSCHI, 2008).

Sobre os fatores de textualidade, Marcuschi (2008) ressalta que devem ser considerados com algumas reservas, ou seja: i. não devem ser divididos de forma tão categórica e estanque, porque alguns são redundantes; ii. não devemos conceber o texto pautado na primazia nem do código nem da forma; e iii. não podemos considerar esses critérios como princípios para se produzir bons textos, como se fossem requisitos necessários a todos, pois há textos, como os literários, por exemplo, que podem não ser coesos e ainda assim serem textos coerentes, dos quais podemos depreender algum sentido (KOCH; TRAVAGLIA, 2004).

"Um texto é uma proposta de sentido e ele só se completa com a participação do seu leitor/ouvinte" (MARCUSCHI, 2008, p. 94). De acordo com Marcuschi (2008), citando Beaugrande (1997), a articulação do texto ocorre em três níveis, quais sejam: linguístico, social e cognitivo; nesse sentido, supomos, no caso da produção/recepção de uma tese em processo de revisão, serem correspondentes a esses níveis, respectivamente, o texto escrito, os lugares ocupados por autor e revisor no âmbito acadêmico e os conhecimentos investidos para produzir/construir sentido(s) mediante a negociação que ocorre nessa etapa da produção textual. 
Marcuschi (2008) ressalta, além disso, que, na distribuição dos fatores de textualidade, encontramos, primeiro, a presença de um autor, de um leitor (falante e ouvinte) e de um texto; segundo, o acesso cognitivo por meio dos aspectos linguísticos (cotextuais: coesão e coerência) e por meio dos conhecimentos de mundo (contextuais: aceitabilidade, informatividade, situacionalidade, intertextualidade e intencionalidade); terceiro, apesar de estarem divididos em dois blocos, esses fatores estão intimamente relacionados.

Ainda a respeito dessa classificação dos fatores de textualidade, Antunes (2010), com base em Beaugrande e Dressler (1981), assume serem 7 (sete) os critérios de textualidade: coesão, coerência, aceitabilidade, informatividade, situacionalidade, intertextualidade e intencionalidade; no entanto, divide-os em dois blocos, da seguinte maneira: coesão, coerência, informatividade e intertextualidade como "propriedades do texto" e a intencionalidade, aceitabilidade e situacionalidade como "condições de efetivação do texto", alegando que a intencionalidade e a aceitabilidade remetem ao interlocutor e que a situacionalidade é uma condição para que o texto aconteça, uma vez que todo texto acontece em um "contexto sociocultural determinado" (ANTUNES, 2010, p. 34).

Costa Val (1999, p. 3), por sua vez, ao definir o texto "[...] ou discurso como ocorrência linguística falada ou escrita, de qualquer extensão, dotada de unidade sociocomunicativa, semântica e formal” (COSTA VAL, 1999, p. 3), entende por semântica a coerência e, por formal, a coesão, sendo a coesão e a coerência dois dos sete fatores de textualidade, caracterizando a textualidade como o conjunto de características que permitem a boa compreensão de um texto. A autora destaca principalmente os fatores coesão e coerência, assumindo que "a coesão é a manifestação linguística da coerência" (COSTA VAL, 1999, p. 6), o modo como os conceitos são expressos na superfície textual. Nessa direção, observamos a relevância do 'acionamento' desses fatores para a interpretação de um enunciado, na relação entre autor-leitor-texto.

Ademais, no âmbito da revisão textual, é possível verificarmos que os movimentos da produção de sentido(s) entre os interlocutores - autor e revisor - possuem um caráter negociativo e, ao mesmo tempo, conflituoso, uma vez que questões de ordem pragmática, cognitiva, cultural, de conhecimento de mundo, de conhecimento partilhado entram em funcionamento nesse processo de produção, recepção e interpretação dos textos, sendo o diálogo entre os parceiros, mesmo que de forma virtual, uma necessidade (BENTES, 2001).

Nesse ínterim, adotamos também um enfoque sociointeracional para refletir sobre a produção de sentido(s) pelo revisor, uma vez que "[...] a textualidade não acontece de forma abstrata. Acontece sob a forma concreta de textos, linguística e socialmente tipificados [...]" 
(ANTUNES, 2010, p. 30). Todo texto expressa um propósito comunicativo, firmado em uma intenção, sendo o resultado de uma atividade social, portanto dialógica - sendo esta uma característica fundamental da linguagem (ANTUNES, 2010; BAKHTIN, 2011, 2014).

Conforme dissemos, o gênero acadêmico tese de doutorado possui caráter dialógico, interacional e polifônico - conceitos que encontramos em Bakhtin. O dialogismo é um princípio constitutivo da própria linguagem para o filósofo, sendo o diálogo sua manifestação clássica e elementar (BAKHTIN, 2011) e o sentido dependente da relação entre os indivíduos e desses com a sociedade (BARROS, 1997). De acordo com Ribeiro (2010, p. 62), “o dialogismo é fator essencial da comunicação, ou seja, apresenta-se como o princípio através do qual há produção e compreensão de sentidos [...]”.

Consoante o pensador russo, o dialogismo desdobra-se em dois aspectos: interação verbal entre enunciadores e no interior dos discursos (BAKHTIN, 2011, 2014). É, pois, na interação entre indivíduos sócio-historicamente situados que ocorre a compreensão, a produção de sentidos. De acordo com Bakhtin (2011, p. 272), "Cada enunciado é um elo na corrente complexamente organizada de outros enunciados"; assim, podemos pressupor, na produção da tese, por exemplo, a presença de uma intertextualidade, ou seja, há diálogo e interação não só entre os indivíduos, interlocutores (autor, orientador, banca, revisor etc.), mas também com outros enunciados/gêneros/textos, neste caso as pesquisas existentes na área, selecionadas e citadas pelo escrevente para corroborar suas palavras, preencher lacunas, apontar horizontes, por meio de uma atitude responsiva. Vale mencionar, ainda, que Bakhtin, no livro sobre Dostoiévski, teoriza a respeito do que seria a noção de polifonia, ou seja, a presença de diferentes vozes no interior do discurso, combinadas a fim de formar o todo (BAKHTIN, 2011, 2018). Ainda que o autor russo estivesse teorizando no campo da literatura, de qualquer modo, pensando na linguagem como um todo, seus conceitos podem ser aplicados também no contexto da produção científica, uma vez que na produção da tese de doutorado são agenciadas diferentes vozes, como dissemos acima, seja para confirmar ou contradizer informações.

Portanto, na seção seguinte, passamos à análise dos dados.

\section{Teses de doutorado em etapa de revisão - análises}

Conforme dissemos na introdução, selecionamos duas teses de doutorado em etapa de revisão: uma concentrada na área de conhecimento das ciências médicas e outra das ciências humanas, tendo sido revisadas por dois profissionais revisores diferentes. Assim, nomeamos o autor e o revisor da primeira tese como "A1" e "R1"; e o autor e o revisor da segunda tese 
como "A2" e "R2". Diante disso, é nosso objetivo, neste artigo, refletir sobre a relevância da negociação entre interlocutores para a construção de sentido, no processo de produção do gênero acadêmico tese de doutorado, em etapa de revisão, numa perspectiva sociointeracionista bakhtiniana, uma vez que esse gênero possui caráter essencialmente dialógico, interacional e polifônico (BAKHTIN, 2011, 2014, 2018).

Para este trabalho, em virtude da extensão do texto, destacamos dois excertos de cada tese, em que aparecem balões, nos quais os revisores “dialogam” com os autores sobre questões que envolvem a interpretação, o sentido. Uma vez que não havia respostas dos autores aos revisores, nos mesmos balões, recolhemos a versão 'final' do texto, pós-revisão, para verificar qual a atitude tomada pelo autor, como forma de resposta - uma atitude responsiva de efeito tardio (BAKHTIN, 2011). Importa ressaltar que trabalhamos com dados processuais, a fim de melhor compreendermos o processo de produção de um texto, em seu status nascendi, acompanhando, portanto, suas etapas, neste caso as diferentes versões originadas ao longo da escrita, tendo em vista um fenômeno específico.

Sendo assim, apresentamos, inicialmente, as duas ocorrências de interação e negociação de sentido(s) retiradas da primeira tese e os respectivos trechos ajustados e, em seguida, as duas ocorrências de interação retiradas da segunda tese.

A Figura 1, portanto, ilustra nosso primeiro excerto, da primeira tese de doutorado. Como vemos, R1 solicita que A1 “Observe esta palavra. [pois] Ela tem conotação negativa”. O comentário do revisor é feito sobre a palavra "diferente", no seguinte trecho da tese: “Apesar das mudanças em relação à percepção da pessoa idosa e da pessoa com deficiência ao longo da história, fica evidente que a sociedade ainda não sabe lidar com o diferente, persistindo ideias e atitudes que refletem a marginalização, o estigma e o preconceito".

Figura 1 - Primeira interação entre A1 e R1

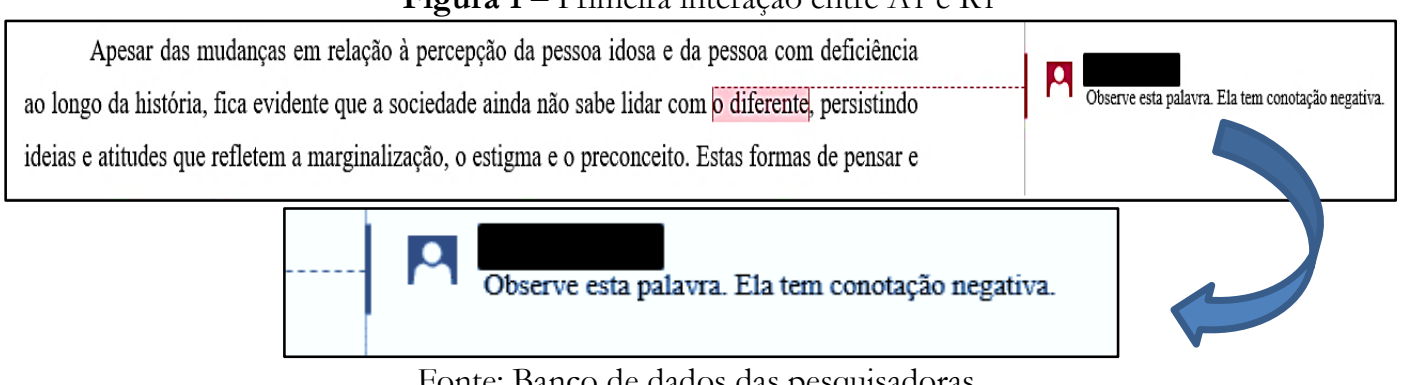

Fonte: Banco de dados das pesquisadoras.

Conforme dissemos na seção anterior, estamos considerando a construção do sentido, na etapa de revisão, especialmente pelo revisor, sob uma perspectiva textual e sociointeracionista. Desta forma, observamos que R1, por meio do comentário embutido no corpo do 
texto, negocia o significado da palavra "diferente" - segundo o dicionário: "Que difere, que se distingue; desigual; diverso"; "Que não é o mesmo nem parecido, que é diverso, não semelhante"; "Em que houve uma mudança ou alteração"; "Fora do comum; especial" (BUENO, 2007, p. 257) -, ao solicitar que "Observe esta palavra", convidando o autor à reflexão, já que "tem conotação negativa".

Sabemos, porém, que o significado das palavras extrapola o dicionário, ganhando sentido(s) com base em seu uso, que é discursivo, de modo que a "[...] conotação é o efeito de sentido pelo qual a escolha de uma determinada palavra ou expressão dá informações sobre o falante, sobre a maneira como ele representa o ouvinte, o assunto e os propósitos da fala em que ambos estão engajados etc.” (ILARI, 2010, p. 41). Notamos, então, que a palavra “diferente” para R1 implica algo ruim, negativo, não sendo aceitável para este interlocutor, ainda que não fosse esta a intenção de A1, sendo a intencionalidade e aceitabilidade condições para efetivação do texto (ANTUNES, 2010).

Ao interagirem, mesmo que virtualmente, no processo de revisão do texto, A1 e R1 negociam sentidos, visto que a dialogia é um fenômeno constitutivo da própria linguagem (BAKTIN, 2011, 2014; BARROS, 1997). Ainda que não haja resposta do autor em um novo balão, neste caso, a versão pós-revisão apresenta a ação deste à solicitação do revisor, como ilustra a Figura 2, a seguir: A1 substitui “diferentes" por “esses fenômenos”, em resposta ao leitor profissional (SALGADO, 2017), marcando a interação entre interlocutores (BAKHTIN, 2011).

Figura 2 - Trecho da primeira interação A1-R1 ajustado

Apesar das mudanças em relação à percepção da pessoa idosa e da pessoa com
deficiência ao longo da história, fica evidente que a sociedade ainda não sabe lidar com esses
fenômenos, persistindo ideias e atitudes que refletem a marginalização, o estigma e 0
preconceito. Estas formas de pensar e agir limita e impede a participação destes grupos de

Fonte: Banco de dados das pesquisadoras.

Assim, conforme a Figura 3, que se segue, apresentamos outra interação entre A1 e R1. Desta vez, solicita especificação a respeito de uma norma da qual se desviam aqueles que não se encaixam no padrão dos que cumprem e atingem metas relacionadas ao trabalho, em razão de doença. De acordo com o revisor: "É bom você citar qual norma”. Rodrigues (2010) informa que, em razão de possuir um conhecimento mais amplo de aspectos gramaticais e de uso da língua, o profissional revisor é capaz de verificar lacunas no texto, 
Figura 3 - Segunda interação entre A1 e R1

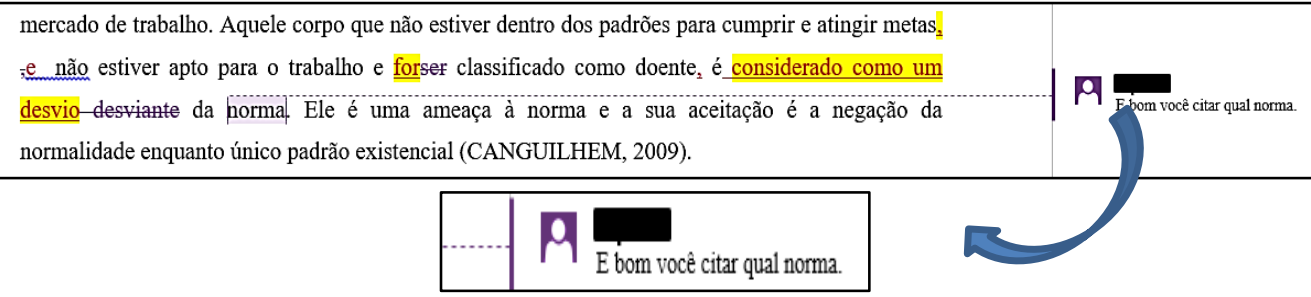

Fonte: Banco de dados das pesquisadoras.

A respeito da negociação, do diálogo no interior do gênero, reafirmamos que o caráter dialógico é constitutivo da própria linguagem, de fundamental importância para a instauração do sentido, o qual depende da relação entre indivíduos e destes com a sociedade (BAKHTIN, 2011, 2014; BARROS, 1997). No interior da tese revisada, verificamos, ainda, que esse diálogo não ocorre somente entre autor e revisor, mas requisita outras vozes, como as de outros autores citados no texto, neste caso "(CANGUILHEM, 2009)", citado no final do parágrafo em questão, sendo esta uma característica de gêneros discursivos produzidos em situações de convívio mais complexo (BAKHTIN, 2011). Diante disso, evidencia-se o caráter interacional, dialógico e polifônico da tese de doutorado, na medida em que sua produção resulta da interação não só entre autor e leitor final, mas também com orientador, banca de qualificação e examinadora, revisor, produções científicas de autores aos quais cita.

Em resposta ao questionamento de R1, A1 reformula a parte final do parágrafo, informando ser "a norma estabelecida pela sociedade capitalista", como mostra a Figura 4, adiante. Em consonância com Marcuschi (2008, p. 94), "Um texto é uma proposta de sentido e ele só se completa com a participação do seu leitor/ouvinte", e o revisor, na condição de leitor profissional com objetivos específicos, pode colaborar com o autor na produção do texto (SALGADO, 2017).

Figura 4 - Trecho da segunda interação A1-R1 ajustado

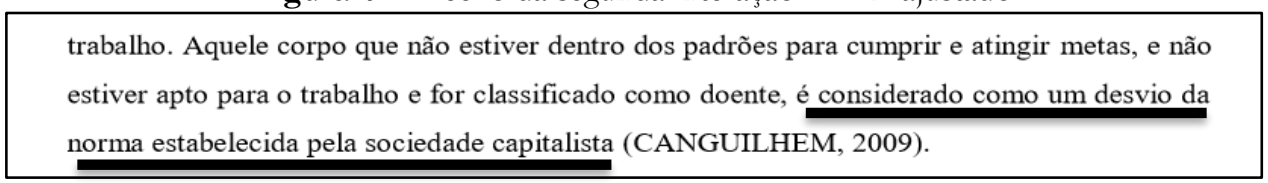

Fonte: Banco de dados das pesquisadoras.

Em seguida, apresentamos dois excertos retirados da segunda tese. Como mostra a Figura 5, embora R2 esteja dando destaque a uma citação direta, ele se atém à conexão, à lógica, quando salienta sobre a passagem "“vitalidade de que dava demonstrações e economia brasileira no início do século XIX", quando afirma que "Esse trecho da citação está 
desconexo com o resto do parágrafo. Seria melhor reelaborar essa parte, pois o trecho 'e economia brasileira do início do século XIX’ não tem sequencia logica [sic] com o restante”.

Figura 5 - Primeira interação entre A2 e R2

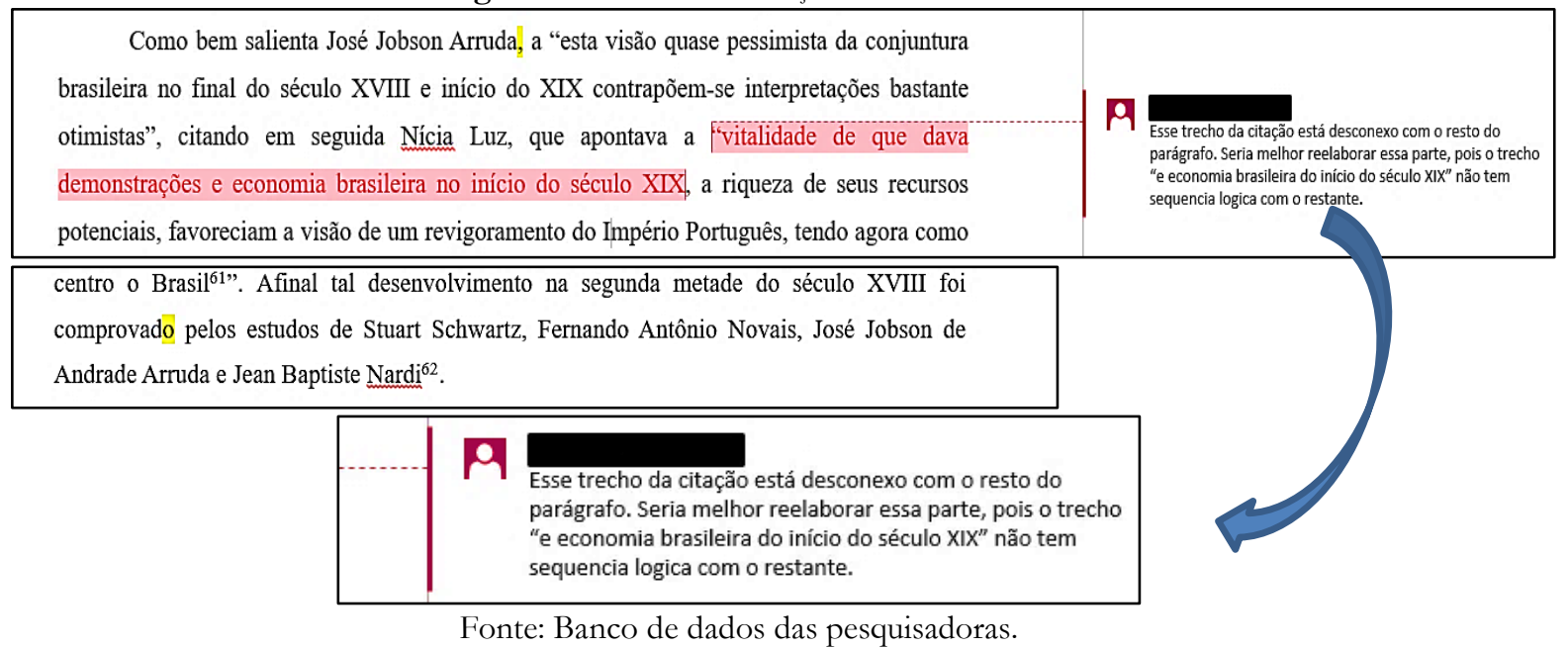

Informamos, na seção anterior, que a compreensão do revisor pode se efetivar em nível textual e sociointeracional. No tocante ao nível textual, recorre aos recursos linguísticos, como a posição de uma vírgula, a seleção de vocábulos, o uso de conjunções, por exemplo; neste caso da figura 5, acreditamos que R2 baseia-se na conexão entre as ideias, naquilo que se encontra na superfície do texto - a coesão - para definir o trecho como desconexo (COSTA VAL, 1999). Visto tratar-se de uma citação direta, não temos certeza se a construção está correta ou não, mas supomos que em lugar da conjunção "e" que liga o trecho destacado pelo revisor deveria ser registrado o artigo "a": "“vitalidade de que dava demonstrações a economia brasileira no início do século XIX”".

Como podemos constatar na Figura 6, adiante, o autor manteve o trecho como estava, uma vez que para reformulá-lo, como propôs R2, teria de transformá-lo em uma paráfrase, não sendo este seu desejo, possivelmente. Ainda que o diálogo tenha sido empreendido, a fim de sanar o problema identificado pelo revisor, de acordo com Marcuschi (2008), contrato e conflito fazem parte da negociação de sentido(s), faz parte da comunicação. Além disso, quando se trata de citações diretas, que constituem as vozes alheias (BAKHTIN, 2011), o mais adequado é que o revisor solicite a conferência do original, para verificação de um possível equívoco na digitação. 
Figura 6 - Trecho da primeira interação A2-R2 ajustado

Como bem salienta José Jobson Arruda, a "esta visão quase pessimista da conjuntura brasileira no final do século XVIII e início do XIX contrapõem-se interpretações bastante otimistas", citando em seguida Nícia Luz, que apontava a "vitalidade de que dava demonstrações e economia brasileira no início do século XIX, a riqueza de seus recursos potenciais, favoreciam a visão de um revigoramento do

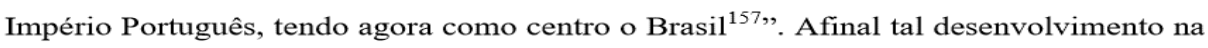

Fonte: Banco de dados das pesquisadoras.

A Figura 7, que se segue, ilustra a segunda ocorrência de interação entre A2 e R2. No balão, à direita, o revisor alerta: “O trecho está sem sentido. Parece estar faltando algo aqui. É preciso reelabora-lo [sic]". O revisor refere-se ao trecho: “com aquelas diferenças acidentais existentes no mesmo cofre todo o resíduo, mas grande parte dele nos referidos depósitos das Inspeções"

Figura 7 - Segunda interação entre A2 e R2

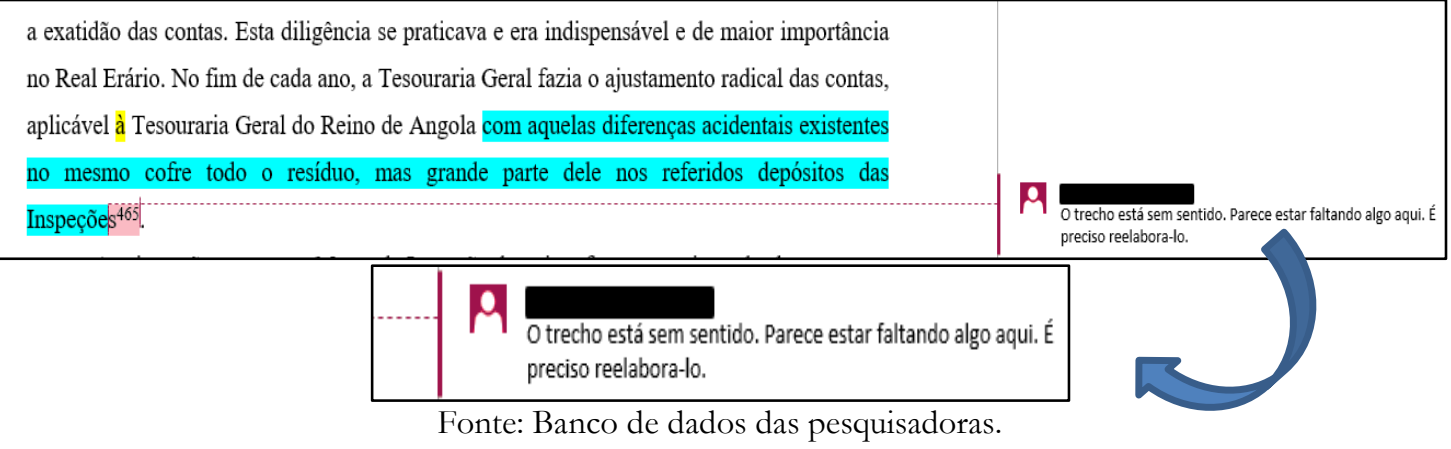

Novamente, observamos que R2 atenta-se para a conexão, para a coesão textual, uma vez que esta manifesta linguisticamente a coerência (COSTA VAL, 1999) e, mediante o diálogo estabelecido por meio do comentário, negocia o sentido com A2, ou seja, solicita sua reelaboração, pois trata-se de paráfrase baseada em obra indicada em nota de rodapé.

Se nos guiarmos pela inferência, diremos que o problema se concentra, especialmente, no trecho "cofre todo o resíduo", o qual poderia ser "cofre de todo o resíduo" - daí o revisor sugerir a falta de algo. Assim, ao verificarmos o mesmo trecho na versão pós-revisão da tese, verificamos que A2 modificou parte do texto, como mostra a Figura 8, seguinte, suprimindo o trecho "todo o resíduo".

Figura 8 - Trecho da segunda interação A2-R2 ajustado contas. Esta diligência se praticava e era indispensável e de maior importância no Real Erário. No fim de cada ano, a Tesouraria Geral fazia o ajustamento radical das contas, aplicável à Tesouraria Geral do Reino de Angola com aquelas diferenças acidentais existentes no mesmo cofre, mas grande parte dele nos referidos depósitos das Inspeções ${ }^{559}$. 
Fonte: Banco de dados das pesquisadoras.

Antunes (2010) adverte que "[...] a textualidade não acontece de forma abstrata. Acontece sob a forma concreta de textos, linguística e socialmente tipificados [...]" (ANTUNES, 2010, p. 30); assim sendo, entendemos que a construção do sentido para o leitor revisor, no processo de revisão, ainda que se trate de texto de área que não seja a de sua formação, não se resume ao conhecimento da "gramática", mas faz-se necessário, também, interagir com seu interlocutor, principalmente porque a dialogia é constitutiva da linguagem e essencial para que haja sentido na relação entre indivíduos e destes com a sociedade em que vivem (BAKHTIN, 2011, 2014; BARROS, 1997).

\section{Conclusão}

Neste artigo, tivemos o interesse de refletir sobre a relevância da negociação entre interlocutores para a construção de sentido, no processo de produção do gênero acadêmico tese de doutorado, em etapa de revisão, numa perspectiva sociointeracionista bakhtiniana, uma vez que esse gênero possui caráter essencialmente dialógico, interacional e polifônico. Nessa perspectiva, ressaltamos a relevância da adequação de linguagem exigida nesse espaço, uma vez que a escola é a principal responsável pelo ensino de língua em sua variedade padrão (POSSENTI, 1996).

Para refletir sobre a construção de sentido(s), na etapa da revisão de textos, consideramo-la sob uma perspectiva textual e sociointeracional, pois, para compreender o texto e 'negociar' com o autor, o revisor se vale de recursos linguísticos, tais como a posição de uma vírgula, a seleção de vocábulos, o uso de conjunções, e também 'dialoga' com o autor do texto, visto que há informações sobre as quais pode não ter conhecimento específico.

A revisão de textos, por sua vez, caracteriza-se como uma atividade profissional ligada aos espaços editoriais, jornalísticos, além de ser considerada, também, uma das etapas de produção de um texto, juntamente com a escrita, reescrita etc. (OLIVEIRA, 2016; RIBEIRO, 2009; YAMAZAKI, 2009). No caso dos trabalhos acadêmicos, a revisão costuma ser feita em caráter freelancer, por um profissional com formação e experiência no tratamento de textos, o qual costuma empreender revisões do tipo resolutivo, indicativo, classificatório e/ou interativo - sendo este último o que nos interessa.

No âmbito acadêmico, conforme dissemos, são produzidos diferentes gêneros discursivos, especialmente os escritos, como artigo, TCC, monografia, dissertação e tese. Assim sendo, analisamos, aqui, alguns excertos de duas teses de doutorado, em etapa de revisão: uma da área das ciências médicas e outra de humanas. Dos trechos analisados, pudemos 
depreender que tanto R1 quanto R2 (Revisor 1 e Revisor 2), ao revisarem as teses, identificam problemas de ordem linguística, no nível da coesão, partindo, posteriormente, para a negociação com os autores, por meio de comentários no interior do texto, a fim de provocar a reflexão sobre escolha de um vocábulo ("diferente"), ao identificar um "período confuso", pela falta de conexão, no caso de R1; e ao solicitar a "reelaboração" de um trecho desconexo ou informar que "O trecho está sem sentido. Parece estar faltando algo", no caso de R2.

Portanto, tendo em vista que a linguagem é constitutivamente dialógica, sendo o dialogismo essencial para a construção de sentido(s) nas interações entre indivíduos e destes com a sociedade, como vimos reafirmando, em uma perspectiva bakhtiniana, salientamos a relevância da negociação entre autor e revisor, na etapa da revisão textual, para a configuração do gênero discursivo tese de doutorado.

\title{
TEXTUAL REVIEW AND ACADEMIC GENRE DOCTORAL DISSERTATION: THE MEANING NEGOTIATION AS THE CORE OF INTERACTION
}

\begin{abstract}
In the academic sphere the production of works, mainly written, is intense, which must be appropriate from the standard language point of view. Based on that, to promote linguistic-discursive adjustments in the text, it is often necessary its textual review. Therefore, our principal aim is to reflect on the relevance of negotiation between interlocutors for the construction of meaning, in the production process of the academic genre doctoral dissertation. Thus, we select two doctoral dissertations, highlighting some excerpts of each, which contain interactions about the meaning, comparing the same revised excerpts with the post-adjustment version. Theoretically, we adopt, therefore, a textual perspective, according to authors such as Costa Val (1999), Marcuschi (2008), Antunes (2010), among others, because we believe that the reviewer is based on linguistic resources in the conduct of his/her activity, and a Bakhtinian social-interactional perspective, since this genre is essentially dialogical, interactional and polyphonic. Based on our analyses, we emphasize, then, the relevance of the negotiation between author and reviewer, in the stage of textual review, to constitute the discursive genre doctoral dissertation, mainly because dialogue represents a constitutive character of language itself and crucial for the execution of meaning.
\end{abstract}

KEYWORDS: Textual review; Negotiation; Discursive genre doctoral dissertation.

\section{REFERÊNCIAS}

ANTUNES, I. Análise de textos: fundamentos e práticas. São Paulo: Parábola Editorial, 2010.

BAKHTIN, M. M. Estética da criação verbal. Prefácio à edição francesa Tzvetan Todorov; introdução e tradução do russo Paulo Bezerra. 6. ed. São Paulo: Editora WMF Martins Fontes, 2011.

BAKHTIN, M. M. O discurso no romance. In: BAKHTIN, M. M. Questões de literatura e estética: a teoria do romance. Tradução de Aurora Fornoni Bernardini et al. 7. ed. São Paulo: Hucitec, 2014. p. 71-210.

BAKHTIN, M. M. Problemas da Poética de Dostoiévski. Tradução direta do russo, notas e prefácio de Paulo Bezerra. 5. ed. Rio de Janeiro: Forense Universitária, 2018.

BARROS, D. L. P. Contribuições de Bakhtin às teorias do discurso. In: BRAIT, B. Bakbtin, dialogismo e construção do sentido. Campinas, SP: Editora da UNICAMP, 1997, p. 27-35. 
BENTES, A. C. Linguística Textual. In: MUSSALIM, F.; BENTES, A. C. (Org.). Introdução à Linguística: domínios e fronteiras, v. 1. São Paulo: Cortez, 2001. p. 245-282

BUENO, S. Minidicionário de Lingua Portuguesa. 2. ed. São Paulo: FTD, 2007.

CÂMARA JR., J. M. História da Lingüística. 6. ed. Petrópolis: Vozes, 1975.

COSTA VAL, M. G. Redação e textualidade. 2. ed. São Paulo: Martins Fontes, 1999. - (Texto e linguagem)

COSTA VAL, M. G. Texto, textualidade e textualização. In: CECCANTINI, J. L. T.; PEREIRA, R. F.; ZANCHETTA JR., J. Pedagogia Cidadã: cadernos de formação: Língua Portuguesa. v. 1. São Paulo: UNESP, Pró-Reitoria de Graduação, 2004. p. 113-128.

GUEDES, L. F. Revisão de textos: conceituação, o papel do revisor textual e perspectivas do profissional do texto. 2013. 13f. Trabalho de Conclusão de Curso (Bacharelado em Letras Português) - Universidade de Brasília, Brasília, 2013.

ILARI, R. Introdução à semântica - brincando com a gramática. 7. ed., $3^{a}$ reimpressão. - São Paulo: Contexto, 2010.

KOCH, I. V.; TRAVAGLIA, L. C. A coerência textual. 16. ed. - São Paulo: Contexto, 2004.

LEMOS, P. S.; PEREIRA, M. H. de M. O gênero textual TCC e a revisão de textos acadêmicos: pontos de contato. Interseções, edição 24, ano 10, número 3 - novembro/2017, p.

216-234. Disponível em: http://www.portal.anchieta.br/revistas-e-livros/interseccoes/pdf/interseccoes-ano-10-numero-3.pdf. Acesso em: 15 jun. 2019.

MELO, P. B. Um passeio pela História da imprensa: o espaço público dos grunhidos ao ciberespaço. Comunicação e Informação, V 8, n 1: p. 26-38. - jan./jun. 2005. Disponível em: https://www.revistas.ufg.br/ci/article/view/24592. Acesso em: 20 jun. 2019. DOI: https://doi.org/10.5216/c\&i.v8i1.24592

MOT'TA-ROTH, D.; HENDGES, G. H. Produção textual na universidade. São Paulo: Parábola Editorial, 2010.

OLIVEIRA, R. R. F. Revisão de textos: da prática à teoria. Natal, RN: EDUFRN, 2016. 159p.: PDF. Disponível em: http://repositorio.efrn.br/jspui. Acesso em: 01 ago. 2019.

POSSENTI, S. Por que (não) ensinar gramática na escola. Campinas, SP: Mercado de Letras: Associação de Leitura do Brasil, 1996. (Coleção Leituras no Brasil)

RIBEIRO, A. E. Em busca do texto perfeito questões contemporâneas da edição, preparação e revisão textual. Divinópolis, MG: Artigo A, 2016.

RODRIGUES, D. L. D. I. Aspectos interacionais dos textos institucionais. Scripta, v. 14, n. 26, p. 151-162. $1^{\circ}$ sem. 2010. Disponível em: http://periodicos.pucminas.br/index.php/scripta/article/view/4357/4502. Acesso em: 12 jul. 2010.

SALGADO, L. S. Quem mexeu no meu texto? Questões contemporâneas de edição, preparação e revisão textual. Divinópolis, MG: Artigo A, 2017.146 p.

SERRANO, F. P. Pesquisar no labirinto: a tese, um desafio possível. Tradução: Marcos Marcionilo. - São Paulo: Parábola Editorial, 2011. 160p. 
YAMAZAKI, C. Edição de texto na produção editorial de livros: distinções e definições. [2009] 231f. Dissertação de Mestrado (Ciências da Comunicação) - Universidade de São Paulo, SP, 2009.

Recebido em: 17/03/2021.

Aprovado em: 02/06/2021. 